\title{
Fast-Track Procedures in Major Orthopaedic Surgery: Is Venous Thromboembolism Prophylaxis Still Mandatory?
}

\author{
Charles Marc Samama ${ }^{1}$ \\ ${ }^{1}$ Department of Anaesthesia and Intensive Care Medicine, Cochin \\ University Hospital, Paris Descartes University, Paris, France \\ Thromb Haemost 2019;119:3-5.
}

Fast-track surgery procedures, also identified as Enhanced Recovery After Surgery, have been challenging evidence-based guidelines on venous thromboembolism (VTE) prophylaxis for several years. ${ }^{1,2}$ They were launched more than 20 years ago by Henrik Kehlet, a Danish orthopaedic surgeon. ${ }^{3,4}$ The project was quite simple and logical: to develop patient-focused procedures that would improve the quality of care and decrease in- and outhospital complications. The programs would coordinate patients care into a multi-modal approach including patient selection, enhanced education, advances in surgical and anaesthetic techniques, post-operative multi-modal analgesia, rehabilitation with early ambulation within 24 hours post-surgery, optimal hydration and discharge in own home. Initially, fasttrack procedures were implemented successfully in many Scandinavian hospitals. ${ }^{5}$ Nowadays, they have shown to be more costeffective than traditional care with shorter length of stay (LOS) while still maintaining equivalent, or better levels of patient satisfaction, low complication and readmission rates. They are more popular in developed countries and, as a result, they represent the standard of care in many institutions, especially for total hip (THR) and total knee replacement (TKR) procedures.

The American College of Chest Physicians (ACCP) has produced guidelines on anti-thrombotic agents for years, ${ }^{6-8}$ and the upcoming ones (the 10th ACCP Guidelines) are on track, now being published chapter by chapter. In the field of VTE prophylaxis, these ACCP guidelines have been the most well-known ones, a kind of Holy Bible for physicians, but many other sets of guidance and guidelines were also available. ${ }^{9,10}$ All of them, with no exception, were recommending an extended prophylaxis (45 weeks) with anticoagulants for THR patients, and 10 to 14 days for TKR patients, some groups suggesting even a longer prophylaxis. These strong recommendations (1A or $1 \mathrm{~B}$ for all of them) were supported by a very strong body of literature showing that VTE events were occurring mainly after patients discharge. Planes et al had shown for the first time in 1996 that 3 weeks of enoxaparin dramatically decreased VTE rates in THR patients, as compared with placebo given at post-operative day 13 to $15 .{ }^{11}$ Other studies had followed and confirmed these data. ${ }^{12}$

\section{received}

November 19, 2018

accepted

November 19, 2018

\begin{abstract}
Address for correspondence Charles Marc Samama, MD, PhD, FCCP, Department of Anaesthesia and Intensive Care Medicine, Cochin University Hospital, 27 rue du Faubourg St Jacques, 75014 Paris, France (e-mail: marc.samama@aphp.fr).
\end{abstract}

However, at that time, by the end of the 1990s, as compared with 2018, fast-track procedures did not exist, and surgical procedures and post-operative inhospital periods were much longer ( 2 hours and 15 days for a THR, respectively). Patients were not mobilized systematically, regional anaesthesia was not so developed and no multi-modal analgesia was available. Obviously, the VTE risk was not the same, as the risk has decreased dramatically. Many data are available among which we have extracted two examples:

- Dahl et al have described annual incidences and 6-month post-operative patterns of clinical VTE in 9,078 patients undergoing major joint surgery in a Scandinavian hospital. ${ }^{13}$ Two cohorts were compared: cohort I (1989-1999) and cohort II (2003-2011). Mean annual VTE incidence was lower in cohort II than in cohort I after THR and hip fracture surgery but not after TKR.

- Partridge et al evaluated 10-year (2005-2014) trends in medical complications following 540,623 primary THR from a national database from England and Wales. ${ }^{14}$ Despite a population with increasing levels of co-morbidity, indicators of quality of care improved from 2005 to 2014. The 90-day mortality rate dropped steadily, from $0.60 \%$ in 2005 to $0.15 \%$ in 2014 . Focusing on VTE, the deep vein thrombosis rate decreased from 1.15 to $0.28 \%$ and the pulmonary embolism (PE) rate from 0.77 to $0.40 \%$.

The message is clear, the disease is now under control in scheduled orthopaedic surgery, thanks to prophylaxis. This also means that the balanced efficacy/safety ratio may shift towards a more important bleeding risk, especially if even more potent anti-thrombotic agents are used.

Keeping these data in mind, the amazing prospective observational cohort by Petersen et al published in the previous issue of the journal is consistent with the above observed trend. ${ }^{15}$ For many years, the authors, including many Danish orthopaedic units (now more than $45 \%$ of the country's units), have developed a successful fast-track approach. Their first preliminary cohort study from 2004

(c) 2019 Georg Thieme Verlag KG Stuttgart · New York
DOI https://doi.org/ $10.1055 / \mathrm{s}-0038-1676613$. ISSN 0340-6245. 
to 2008 in approximately 2,000 fast-track THR and TKR with a mean LOS of 3 to 7 days and inhospital-only thromboprophylaxis, found comparable or lower incidences of VTE than previously reported with prolonged thromboprophylaxis. ${ }^{16}$ The first large report was published in $B M J$ in $2013,{ }^{17}$ and at that time, only 4,718 patients undergoing THR or TKR surgery were included. The median LOS was 2 days (interquartile range: $2-3$ days), meaning already that prophylaxis was given for 2 days in half of the patients. VTE event rates were found to be very low when assessed at 3 months. Indeed, they were quite different and much increased in the small sub-set of patients whose LOS was greater than 5 days. Since then studies have included more patients, and other reports have also been published. Now, Petersen et al confirm all these data with a large cohort of 18,407 procedures in 16,808 patients. Prophylaxis with low-molecularweight heparin (LMWH), fondaparinux or oral factor Xa inhibitors was only given during hospitalization, that is, when LOS was $\leq 5$ days ( $94.6 \%$ of the total of procedures). As in the previous reports, none of the participating departments utilized intermittent pneumatic compression (IPC) devices or compression stockings. The results look as copypasted from the BMJ report, but thrice the patient population, which confirm the quality of these data. The 90-day incidence of VTE after fast-track THR and TKR with inhospital-only thromboprophylaxis reached $0.40 \%$. Petersen et al. used 90-day mortality as a safety outcome and found that only two patients suffered from a fatal PE. In addition, as already observed in the 2013 report, patients with a much longer LOS developed much more important thrombotic risks and co-morbidities (any VTE: 2.33\%). The authors emphasize that the incidence of VTE in fast-track total hip arthroplasty/total knee arthroplasty appears to be similar or perhaps even lower compared with the previous randomized controlled trials (RCTs) on which most international guidelines are based.

These reassuring data coming from a large, but only observational, cohort raise some questions:

- The authors conclude that prolonged thromboprophylaxis may be reserved for LOS greater than 5 days or for specific high-risk patients. How could this higher risk population be identified? As their study is not controlled, this assumption should be taken with prudence.

- Is there any rationale for giving a very short prophylaxis? Unpublished reports from this Danish group (and others) state that the median LOS is still decreasing for THR and TKR patients, now being close to '1 day' in 2018. More and more procedures are also performed on an ambulatory basis. Thus, is prophylaxis given only once in these fast-track patients? Is the minimal VTE rate only related to the fast-track procedures? Do ambulatory patients receive any prophylaxis?

- Further studies regarding optimal type and duration of thromboprophylaxis should be proposed. However, even if the VTE risk was low in the Petersen cohort, all the patients did receive a (short) prophylaxis, namely, rivaroxaban, enoxaparin, dalteparin and fondaparinux, precluding any withdrawal of prophylaxis. In addition, would any ethical committee approve a RCT comparing the usual prophylaxis procedure with the absence of prophylaxis?

- Could a therapeutic de-escalation be the solution? The interest in aspirin has increased in the United States since the 2012 ACCP guidelines prompted aspirin at the same level of safety and efficacy with that of conventional treatments (LMWH, fondaparinux, direct oral anticoagulants; grade $1 \mathrm{~B}){ }^{8}$ Since, numerous large North American cohorts and meta-analyses have been published showing that

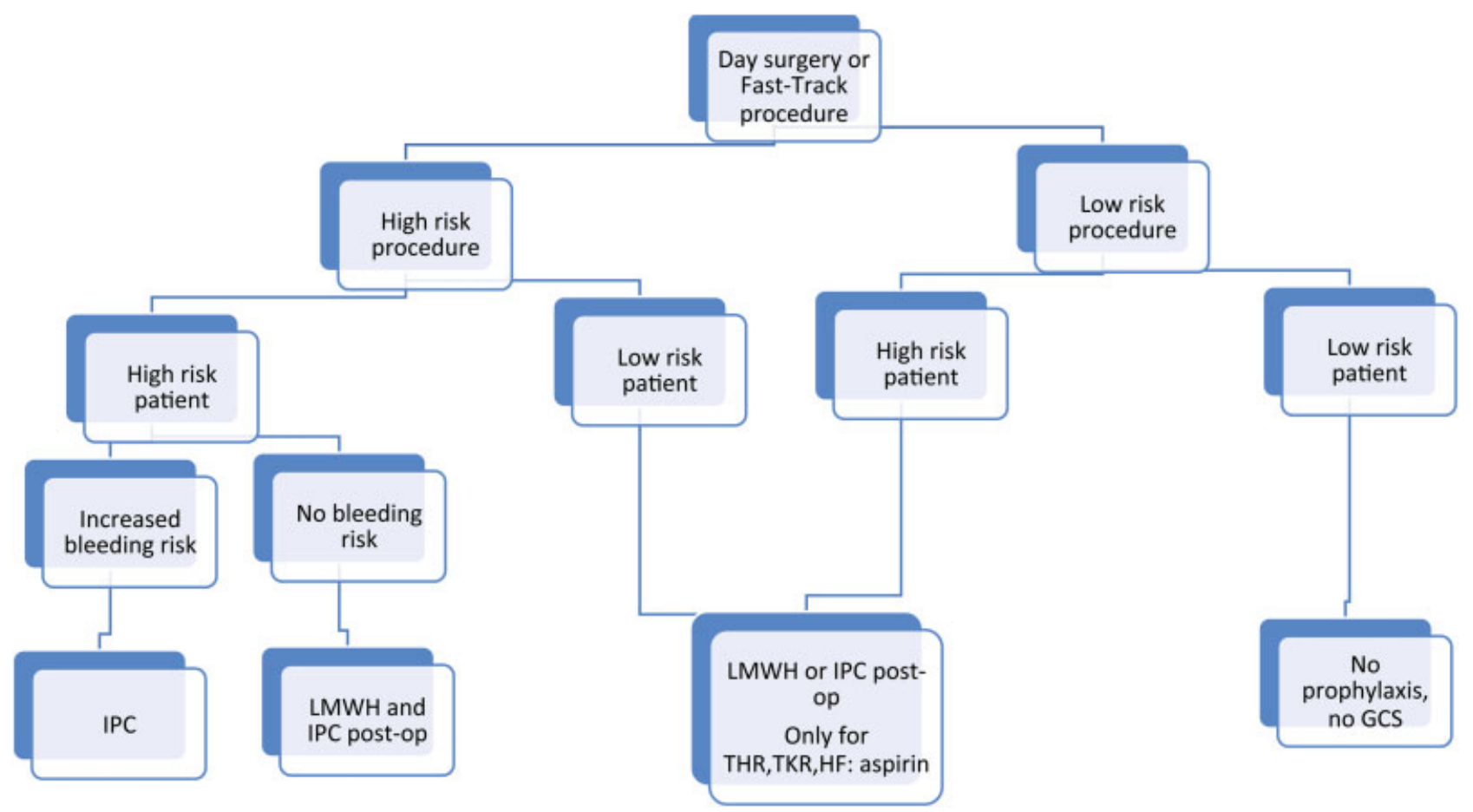

Fig. 1 Proposals from the ESA VTE Guidelines on VTE prophylaxis. GCS, graduated compression stockings; LMWH, low molecular weight heparin; IPC, intermittent pneumatic compression; THR, total hip replacement; TKR, total knee replacement; HF, hip fracture. 2,21,23 
aspirin is non-inferior to anticoagulants in THR and TKR patients. ${ }^{18,19}$ In addition, a large multi-centre randomized trial comparing low-dose aspirin with warfarin and rivaroxaban is on-going, planning to enrol 25,000 patients (the Comparative Effectiveness of Pulmonary Embolism Prevention After Hip and Knee Replacement [PEPPER] trial; NCT02810704-Estimated Study Completion Date 2021). It will provide evidence-based data and will help to answer the question about the efficacy/safety ratio of aspirin. Already, the recent VTE guidelines from the European Society of Anaesthesiology suggest the use of aspirin in fast-track orthopaedic procedures (grade 2C). 20,21

- Last but not least, IPC is very effective: ${ }^{22,23}$ could it be also part of the future of prophylaxis? Combining IPC with other methods represent an increasing trend in the prophylactic practice.

Some practical proposals can be made and are shown in -Fig. 1.

Currently, there is not enough evidence yet to withhold prophylaxis in these patients. Fatal PE has almost disappeared from orthopaedic surgery units, and no one wishes to see PE back in our wards. Only evidence-based studies will change the daily clinical practice and provide further data on the optimal type of prophylaxis and its best duration. Definitely, still a lot of work has to be done to confirm the observed efficacy of shorter term prophylaxis, aspirin and IPC in these patients, but both appear to be interesting solutions in this clinical setting. We now have to cope with all these new challenges and intensify the research in the field. Then, guidelines may change dramatically...

\section{Conflict of Interest}

None declared.

\section{References}

1 Eikelboom JW, Karthikeyan G, Fagel N, Hirsh J. American Association of Orthopedic Surgeons and American College of Chest Physicians guidelines for venous thromboembolism prevention in hip and knee arthroplasty differ: what are the implications for clinicians and patients? Chest 2009;135(02):513-520

2 Venclauskas L, Llau JV, Jenny J-Y, Kjaersgaard-Andersen P, Jans Ø; ESA VTE Guidelines Task Force. European guidelines on perioperative venous thromboembolism prophylaxis: day surgery and fast-track surgery. Eur J Anaesthesiol 2018;35(02):134-138

3 Kehlet H. Multimodal approach to control postoperative pathophysiology and rehabilitation. Br J Anaesth 1997;78(05):606-617

4 Kehlet H. Fast-track surgery-an update on physiological care principles to enhance recovery. Langenbecks Arch Surg 2011; 396(05):585-590

5 Berg U, BüLow E, Sundberg M, Rolfson O. No increase in readmissions or adverse events after implementation of fast-track program in total hip and knee replacement at 8 Swedish hospitals: an observational before-and-after study of 14,148 total joint replacements 2011-2015. Acta Orthop 2018;89(05):522-527

6 Geerts WH, Pineo GF, Heit JA, et al. Prevention of venous thromboembolism: the Seventh ACCP Conference on Antithrombotic and Thrombolytic Therapy. Chest 2004;126(3, Suppl):338S-400S

7 Geerts WH, Bergqvist D, Pineo GF, et al. Prevention of venous thromboembolism: American College of Chest Physicians Evi-
dence-Based Clinical Practice Guidelines (8th ed.). Chest 2008; 133:381S-453S

8 Falck-Ytter Y, Francis CW, Johanson NA, et al. Prevention of VTE in orthopedic surgery patients: Antithrombotic Therapy and Prevention of Thrombosis, 9th ed: American College of Chest Physicians Evidence-Based Clinical Practice Guidelines. Chest 2012; 141(2, Suppl):e278S-e325S

9 Treasure T, Hill J. NICE guidance on reducing the risk of venous thromboembolism in patients admitted to hospital. J R Soc Med 2010;103(06):210-212

10 Samama C-M, Gafsou B, Jeandel T, et al; French Society of Anaesthesia and Intensive Care. French Society of Anaesthesia and Intensive Care. Guidelines on perioperative venous thromboembolism prophylaxis. Update 2011. Short text [in French]. Ann Fr Anesth Reanim 2011;30(12):947-951

11 Planes A, Vochelle N, Darmon JY, Fagola M, Bellaud M, Huet Y. Risk of deep-venous thrombosis after hospital discharge in patients having undergone total hip replacement: double-blind randomised comparison of enoxaparin versus placebo. Lancet 1996;348 (9022):224-228

12 Eikelboom JW, Quinlan DJ, Douketis JD. Extended-duration prophylaxis against venous thromboembolism after total hip or knee replacement: a meta-analysis of the randomised trials. Lancet 2001;358(9275):9-15

13 Dahl OE, Gudmundsen TE, Pripp AH, Aanesen JJ. Clinical venous thromboembolism following joint surgery: effect of extended thromboprophylaxis on its annual frequency and postoperative pattern over 22 years. Clin Appl Thromb Hemost 2014;20(02):117-123

14 Partridge T, Jameson S, Baker P, Deehan D, Mason J, Reed MR. Tenyear trends in medical complications following 540,623 primary total hip replacements from a national database. J Bone Joint Surg Am 2018;100(05):360-367

15 Petersen PB, Kehlet H, Jørgensen CC; on behalf of the Lundbeck Foundation Centre for Fast-track Hip and Knee Replacement Collaborative Group. Safety of in-hospital only thromboprophylaxis after fast-track total hip and knee arthroplasty: a prospective follow-up study in 17,582 procedures. Thromb Haemost $2018 ; 118(12): 2152-2161$

16 Husted H, Otte KS, Kristensen BB, Ørsnes T, Wong C, Kehlet H. Low risk of thromboembolic complications after fast-track hip and knee arthroplasty. Acta Orthop 2010;81(05):599-605

17 Jørgensen CC, Jacobsen MK, Soeballe K, et al. Thromboprophylaxis only during hospitalisation in fast-track hip and knee arthroplasty, a prospective cohort study. BMJ Open 2013;3(12):e003965

18 Wilson DGG, Poole WEC, Chauhan SK, Rogers BA. Systematic review of aspirin for thromboprophylaxis in modern elective total hip and knee arthroplasty. Bone Joint J 2016;98-B(08):1056-1061

19 Hood BR, Cowen ME, Zheng HT, Hughes RE, Singal B, Hallstrom BR. Association of aspirin with prevention of venous thromboembolism in patients after total knee arthroplasty compared with other anticoagulants: a noninferiority analysis. JAMA Surg 2018. Doi: 10.1001/jamasurg.2018.3858

20 Samama CM, Afshari A; ESA VTE Guidelines Task Force. European guidelines on perioperative venous thromboembolism prophylaxis. Eur J Anaesthesiol 2018;35(02):73-76

21 Jenny J-Y, Pabinger I, Samama CM; ESA VTE Guidelines Task Force. European guidelines on perioperative venous thromboembolism prophylaxis: aspirin. Eur J Anaesthesiol 2018;35(02):123-129

22 Dennis M, Sandercock P, Reid J, Graham C, Forbes J, Murray G; CLOTS (Clots in Legs Or sTockings after Stroke) Trials Collaboration. Effectiveness of intermittent pneumatic compression in reduction of risk of deep vein thrombosis in patients who have had a stroke (CLOTS 3): a multicentre randomised controlled trial. Lancet 2013;382(9891):516-524

23 Afshari A, Fenger-Eriksen C, Monreal M, Verhamme P; ESA VTE Guidelines Task Force. European guidelines on perioperative venous thromboembolism prophylaxis: mechanical prophylaxis. Eur J Anaesthesiol 2018;35(02):112-115 